\title{
AL Amyloidosis with Renal Involvement
}

\author{
Romana Ryšavá \\ Nephrology Clinic, 1st Faculty of Medicine, Charles University, Prague, Czech Republic
}

\section{Key Words}

Amyloid $\cdot$ AA amyloidosis $\cdot$ AL amyloidosis $\cdot$ Nephrotic syndrome $\cdot$ Stem cell transplantation $\cdot$ High-dose melphalan

\section{Abstract}

Primary (AL amyloidosis) is a systemic disease characterized by an amyloid deposition process in many organs, with unsatisfactory survival of patients. The monoclonal light chains form the fibrils that deposit and accumulate in tissues. Renal involvement is very frequent in $\mathrm{AL}$ amyloidosis and could lead to development of nephrotic syndrome followed by the renal failure in many cases. Classic therapeutic combination melphalan and prednisone has been supplemented with drugs with different mechanisms of action in this group of patients: high-dose dexamethasone, high-dose dexamethasone with melphalan, combination of vincristine, doxorubicin, and dexamethasone or newly high-dose melphalan supported by peripheral blood stem cell transplantation. This progressive therapy leads to the better survival and prognosis in the majority of patients. Alternative therapeutic approaches include thalidomide (alone or in combination with cyclophosphamide), lenalidomide, iododoxorubicin, etanercept and rituximab. The development of immunotherapy is expected in the near future. Copyright $\odot 2007 \mathrm{~S}$. Karger $\mathrm{AG}$, Basel
\end{abstract}

This study was supported by the research project of MH Czech Republic (MZO 00023728) and an unrestricted educational grant provided by Amgen.
(C) 2007 S. Karger AG, Basel

$1420-4096 / 07 / 0306-0359 \$ 23.50 / 0$

Fax +4161306 1234

E-Mail karger@karger.ch

www.karger.com
Accessible online at:

www.karger.com/kbr

\section{Introduction}

AL amyloidosis is a result of the clonal plasma cell disorder with an incidence of about 10 persons per million per year [1]. It is the most common and most severe form of systemic amyloidosis. Amyloid deposits containing the light chain (LC) infiltrate the tissues and cause their dysfunction and failure. The most affected organs are kidneys (74\%), heart (60\%), gastrointestinal tract (10$20 \%)$, liver (27\%) and autonomic nervous system (18\%). $69 \%$ of patients had more than one affected organ at the time of diagnosis [2]. Without therapy the median survival is $10-13$ months from the time of diagnosis assessment and the survival shortens to 6 months in the group of patients with cardiac involvement [1].

The optimal management of patients with AL requires early diagnosis, correct assessment of the type of amyloid, extent of organ involvement, effective treatment with supportive therapy and a very careful follow-up. The activity of the disease and the hematological response to the treatment could be monitored by plasma levels of monoclonal proteins (MP). Screening electrophoresis is inadequate, since $56 \%$ of patients do not have a detectable monoclonal spike. All patients might be screened by immunofixation. Unlike multiple myeloma, in which the majority of patients have a quantifiable amount of MP, many patients with AL amyloidosis do not have a measurable level of MP. The serum level of MP exceeds 1.5 $\mathrm{g} / \mathrm{l}$ in only about $10 \%$ of AL patients. A new method for quantitative measurement of free light chains (FLC) has recently been developed for the detection of MP. This method, using the nephelometric assay, is able to detect

Assoc. Prof. Romana Ryšavá, $\mathrm{MD}, \mathrm{PhD}$

Klinika nefrologie, VFN

U nemocnice 2, CZ-128-08 Prague 2 (Czech Republic)

Tel. +420 224962587, Fax +420224962585

E-Mail rysavar@vfn.cz 
Table 1. The most frequent types of amyloidosis (nomenclature, fibril proteins and precursors)

\begin{tabular}{|c|c|c|c|}
\hline $\begin{array}{l}\text { Amyloid } \\
\text { protein }\end{array}$ & Precursor & $\begin{array}{l}\text { Systemic (S) } \\
\text { or localized } \\
\text { (L) form }\end{array}$ & Syndrome or involved organs \\
\hline$A \beta$ & $\mathrm{A} \beta$ protein precursor $(\mathrm{A} \beta \mathrm{PP})$ & $\mathrm{L}$ & $\begin{array}{l}\text { Alzheimer's disease } \\
\text { Cerebral amyloid angiopathy (Dutch type) }\end{array}$ \\
\hline $\mathrm{APrP}$ & Prion protein & $\mathrm{L}$ & Spongiform encephalopathies \\
\hline ABri & ABri protein & $\mathrm{L}(\mathrm{S})$ & Familial dementia (British type) \\
\hline ACys & Cystatin C & $\mathrm{S}$ & Cerebral amyloid angiopathy (Island type) \\
\hline$A \beta_{2} M$ & $\beta_{2}$-Microglobulin & S & Dialysis associated \\
\hline $\mathrm{AL}(\mathrm{AH})$ & $\begin{array}{l}\text { Light (heavy) chains of } \\
\text { immunoglobulins }\end{array}$ & $\mathrm{S}(\mathrm{L})$ & $\begin{array}{l}\text { Primary amyloidosis } \\
\text { (myeloma associated) }\end{array}$ \\
\hline AA & Serum amyloid A & $\mathrm{S}$ & Secondary (reactive) amyloidosis \\
\hline ATTR & Transthyretin & $\mathrm{S}$ & $\begin{array}{l}\text { Familial amyloid polyneuropathy } \\
\text { Senile systemic }\end{array}$ \\
\hline AApoAI & Apolipoprotein AI & $\begin{array}{l}\mathrm{S} \\
\mathrm{L}\end{array}$ & $\begin{array}{l}\text { Familial (kidney, liver, heart) } \\
\text { Aorta }\end{array}$ \\
\hline AApoAII & Apolipoprotein AII & S & Familial (kidney, heart) \\
\hline AGel & Gelsolin & $\mathrm{S}$ & Familial (Finnish type) \\
\hline ALys & Lysozyme & $\mathrm{S}$ & Familial (kidney, liver, spleen) \\
\hline AIÁPP & Islet amyloid polypeptide & $\mathrm{L}$ & $\begin{array}{l}\text { Islets of Langerhans (diabetes mellitus, } \\
\text { insulinomas) }\end{array}$ \\
\hline AFib & Fibrinogen $\alpha$-chain & $S$ & Familial \\
\hline
\end{tabular}

Modified according to Westermark et al: Amyloid: toward terminology clarification. Report from the Nomenclature Committee of International Society of Amyloidosis. Amyloid 2005;12:1-4.

only small concentrations of FLC in patients with plasma cell disorders, including multiple myeloma and AL amyloidosis. The investigation of bone marrow is necessary to exclude the diagnosis of multiple myeloma or amyloid deposits in the bone marrow. Cardiac dysfunction may be characterized by increasing in concentrations of $\mathrm{N}$ terminal pro-brain natriuretic peptide (NT-proBNP) and cardiac troponins [3].

\section{Pathophysiology of Amyloid Formation}

Amyloidoses represent a wide group of protein-folding disorders in which normally soluble proteins are deposited as insoluble fibrils in many organs, where they interfere with the structural integrity and function of targeted tissues. Amyloid deposits are composed of protein fibrils, the peptide subunits of which differ in different forms of amyloidoses. More than 20 different types of the fibrils form the basis for the classification of the clinical amyloidosis syndromes. Amyloidoses could be also divided into localized and systemic forms (table 1). Alzheimer's disease is the most common and typical repre- sentative of the localized form of amyloidosis, with $\beta$ protein deposits found in the brain, while systemic forms of amyloidoses may affect all tissues except the brain.

Glycosaminoglycans (GAG), predominantly heparan sulfate and dermatan sulfate, are the second major components of amyloid deposits, which bind tightly, but noncovalently to the amyloid fibrils. Amyloid P component (AP) is a minor, but a very important part of amyloid deposits with glycoprotein non-fibrillar structure. AP is derived from a circulating precursor serum AP (SAP), which belongs to the acute phase proteins. SAP binds reversibly to all types of amyloid fibrils through a specific calcium-dependent receptor [4]. Apolipoproteins E and J and amyloid-enhancing factor complete the list of components forming amyloid deposits. Amyloid deposits infiltrate various tissues as hyaline eosinophilic material localized extracellularly and have a $\beta$-pleated sheet conformation.

The deposits in AL amyloidosis containing the fibrils consist of fragments of the variable portion of monoclonal LC. Although this disorder is associated with the single clone of proliferating plasma cells, most patients do not develop the malignant disease as multiple myeloma, 


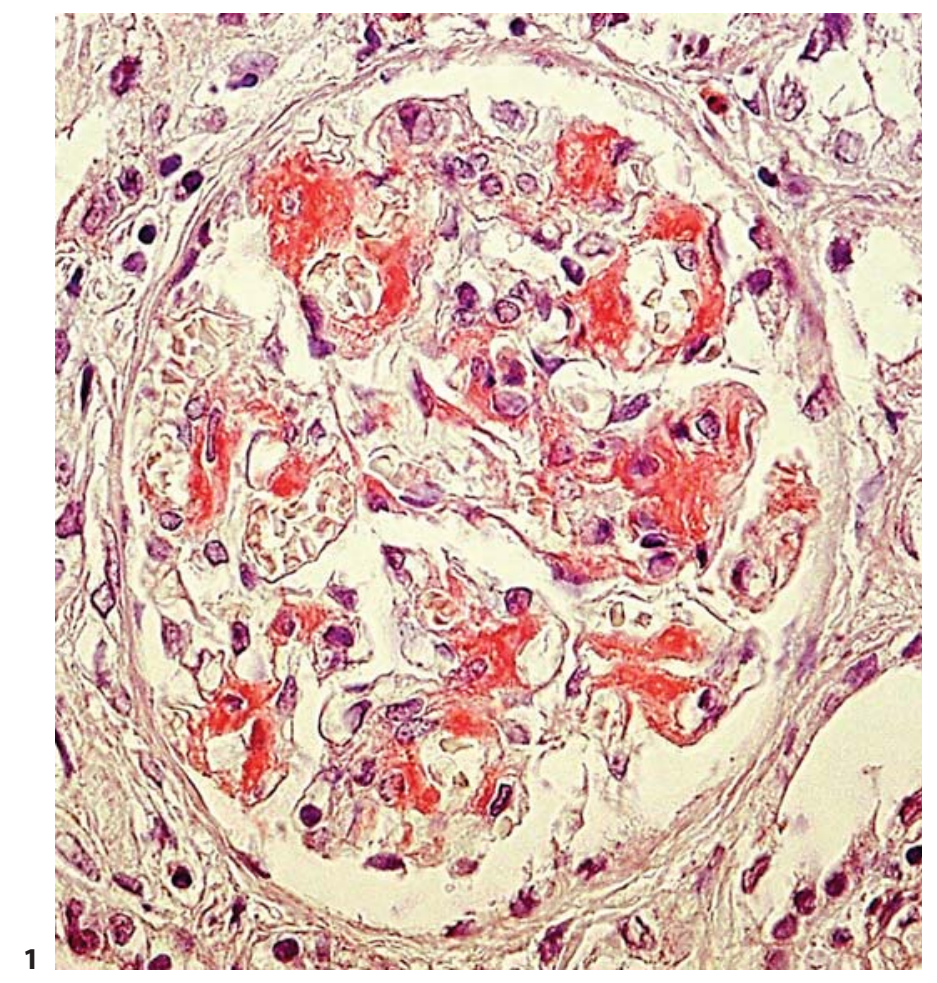

but have only monoclonal gammopathy, which is classified as monoclonal gammopathy of undetermined significance (MGUS). This observation indicates that some additional factors are required for development of amyloid deposits. One such property is the ability to be digested by macrophages, where intact LCs are metabolized to insoluble and unstable fragments with biochemical properties that allow them to form amyloid fibrils. The LC $\lambda$ are more amyloidogenic than $\kappa$ ones. LC $\kappa$ have the tendency to form the granular tissue deposits resulting in so-called LC deposition disease [5].

\section{Renal Involvement in Amyloidosis and Diagnosis}

AL amyloidosis represents the systemic form of amyloidosis, in which the infiltration of kidneys by amyloid deposits occurs as an early and common event. Renal involvement in amyloidosis usually manifests as nephrotic syndrome in the majority of cases with normal renal function. The rate of progression to renal failure is usually slow, but depends directly on the intensity of proteinuria and extension of amyloid deposits, especially in the vessels and tubules. If the deposits are primarily localized to the vessels, there is little or no proteinuria but renal

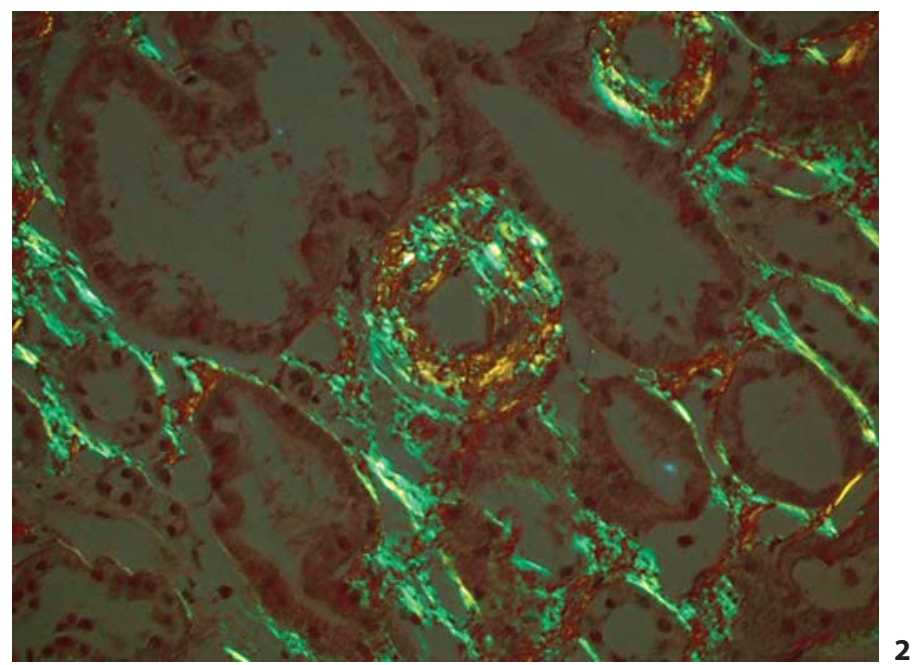

Fig. 1. Mesangial matrix of glomerulus affected by amyloid deposits. Congo red staining.

Fig. 2. Glomerular LC $\lambda$ deposits in AL amyloidosis. Immunofluorescence with anti- $\lambda$ antibody. insufficiency is commonly due to decreased glomerular perfusion.

A diagnosis of amyloidosis has to be assessed histologically from biopsy specimens. Positive staining for Congo red and fibrillar appearance by electron microscopy is the common property of all types of amyloidoses (fig. 1). Congo red-positive staining leads to the applegreen birefringence under the polarized light microscopy (fig. 2). Immunofluorescence microscopy is typically positive for monoclonal LC $\kappa$ or $\lambda$ in AL amyloidosis, while anti-AA antibody (typical for secondary AA amyloidosis) is negative (fig. 3). Deposition of predominantly variable, rather than the constant region explains why immunofluorescence microscopy with anti- $\lambda$ or anti- $\kappa$ LC antibodies is sometimes only weakly positive.

Light microscopy in renal amyloidosis typically reveals diffuse glomerular deposition of amorphous hyaline material, especially in the mesangium and also in capillary loops. Amyloid deposits could be seen in the small arteries, arterioles and later on also in the tubular basement membrane. Although radionuclide imaging methods using ${ }^{99 \mathrm{~m}} \mathrm{Tc}$ aprotinin or iodinated SAP can be used to detect and image the deposits, these methods cannot replace the histological proof of amyloid deposits and are not widely available [6]. 


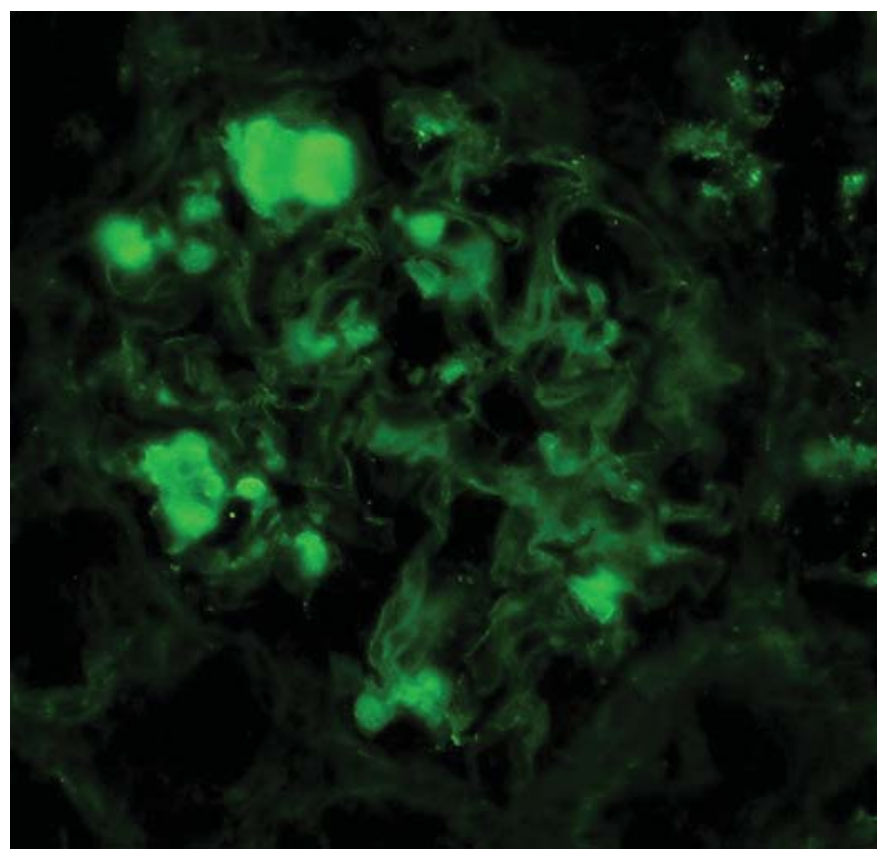

Fig. 3. Amyloid deposits in arterial wall and tubular basement membrane. Congo red under polarized microscopy.

\section{Definition of Renal Involvement and Treatment Response in AL Amyloidosis}

Kidney involvement is defined as presence of amyloid deposits in renal biopsy with clinical and laboratory evidence of kidney dysfunction or bioptically proven amyloid deposits in other organs from alternative biopsy specimens (abdominal fat, bone marrow, rectum, gingiva, etc.) associated with urinary protein excretion $\geq 0.5$ $\mathrm{g} /$ day. Other causes of proteinuria (diabetes mellitus, uncontrolled hypertension or some autoimmunity) must be excluded. Renal response to the treatment is defined as $50 \%$ reduction (at least $0.5 \mathrm{~g} /$ day) of 24 -hour urinary protein excretion (on the condition that urinary protein is $>0.5 \mathrm{~g}$ /day initially) in parallel with the stable creatinine and creatinine clearance (both cannot worsen by $25 \%$ over baseline) [7].

\section{Therapeutic Possibilities in AL Amyloidosis}

There are several different targets which could be potentially influenced by our therapeutic interventions in the treatment of amyloidoses. First, there is the overproduction of structurally normal protein precursors or quantitatively normal production of structurally abnormal proteins, which might be diminished. Second, the binding of SAP or GAG to the amyloid fibrils, affecting the formation of fibril aggregates, could be blocked.

Since AL amyloidosis develops as a result of neoplastic expansion of the plasma cell population synthesizing the amyloidogenic LCs, the primary therapeutic target remains to be the pathological clone. The crucial clinical endpoint in amyloidosis is organ response. It is clear that the amyloid in organs cannot resolve until the production of precursors has been diminished. After the discontinuation of MP production a slow resolution of amyloid deposits from the tissues (if the organ damage is not irreversible) can be observed [8].

Chemotherapy regimens in $\mathrm{AL}$ are based on those used in multiple myeloma despite the fact that the plasma cell dyscrasia in most AL patients is relatively benign and also less chemosensitive. The standard therapy used for more than 30 years is represented by the combination of melphalan $(0.15-0.25 \mathrm{mg} / \mathrm{kg})$ and prednisone $(1 \mathrm{mg} / \mathrm{kg})$ for 4 days, repeated every 28 days. This relatively myelotoxic therapy is recommended to be administered for a minimum of 12 months and a maximum of 24 months. Prolongation of treatment is accompanied by the dramatic increase in the incidence of acute leukemia and myelodysplastic syndrome [4]. The treatment with highdose dexamethasone (40 $\mathrm{mg}$ of dexamethasone/day on days $1-4,9-12$ and 17-20) is less toxic than melphalan and prednisone with the similar response rate. The combination of high-dose dexamethasone with melphalan is more effective than the previous treatments for the patients ineligible for stem cell transplantation [9]. 67\% of patients may achieve a hematological response and 33\% of patients may achieve a complete hematological remission. In $48 \%$ of patients, functional/organ improvement can be observed after this treatment combination.

VAD (vincristine, doxorubicin, dexamethasone) or CVAD (cyclophosphamide + VAD) have been reported in $\mathrm{AL}$ amyloidosis as a rescue therapy in severe forms of $\mathrm{AL}$ not indicated for stem cell transplantation (including those with myocardial involvement, despite doxorubicin itself being cardiotoxic) [4].

Many centers all over the world currently use highdose chemotherapy with stem cell transplantation as the standard/basic treatment for patients with AL $[10,11]$. The patients have to be carefully examined for eligibility for this procedure in order to minimize high peritransplant mortality. Patients at very high risk are those older than 65 years, with more than two affected organs, with significant hypotension (systolic blood pressure $\leq 90$ 
$\mathrm{mm} \mathrm{Hg}$ ) or syncopes, with ejection fraction of left ventricle $<45 \%$ or thickness of interventricular septum $\geq 15$ $\mathrm{mm}$ [12]. The dose of chemotherapy with melphalan is calculated according to the renal function, age and myocardial involvement (between 100 and $200 \mathrm{mg} / \mathrm{m}^{2}$ ). Despite the fact that cardiac, liver and kidney function in patients eligible for transplantation is relatively better (compared with those not selected), the treatment-related mortality in many centers recently oscillated around 10 $15 \%$. The response to the treatment is very important for the survival. Median survival for patients with more than two organs involvement at the time of transplantation is 21.5 months, and for those with involvement of only one organ exceeds 6 years $[8,13]$. Longer survival in the group of patients undergoing the stem cell transplantation could be partly explained by strict patient selection. In a casematched control study from Mayo Clinic on a cohort of $126 \mathrm{AL}$ patients (63 patients with transplantation, 63 not undergoing transplantation; there was no difference between the groups in sex, age and organ involvement) a significantly longer survival in the group of patients undergoing peripheral blood stem cell transplantation compared with the control group (the majority of patients in this group were treated with alkylating chemotherapy) could have been demonstrated. One- and 4-year survival in the transplant and control group was 89 vs. 71 and 71 vs. $41 \%$ respectively [14].

Alternative therapeutic approaches include blockade of TNF- $\alpha$ (soluble receptor - etanercept) and blockade of plasma cells (anti-CD20 antibody rituximab). Thalidomide, that probably acts through the blockade of TNF- $\alpha$, VEGF (vascular endothelial growth factor) and NF- $\kappa \mathrm{B}$ (nuclear factor- $\mathrm{KB}$ ) are reserved for high-risk patients, especially where stem cell transplantation failed [13]. These drugs are now being tested within different clinical trials. Also, drugs effective in multiple myeloma, bortezomib (proteasome inhibitor) and lenalidomide (similar effect as thalidomide), are usually active in AL amyloidosis [15].

I-DOX (4'-iodo-4'-deoxydoxorubicin), an iodinated anthracycline derivate, binds specifically and with high affinity to the natural fibrils and promotes their disaggregation. Its positive therapeutic effect has been observed predominantly in soft tissues as tongue, skin and genitals, with only a sparse effect in parenchymal organs - liver, kidneys and spleen [16].

Heart transplantation should be mentioned as the last therapeutic modality in patients with severe amyloid heart disease. This palliative procedure remains controversial due to a very high postoperative mortality $(20 \%)$ and 5-year survival not exceeding 30\% [17]. Many centers additionally recommend the necessity of posttransplant treatment with high-dose chemotherapy and stem cell support during the 6-month period after heart transplantation [18].

Causal treatment for the renal involvement in $\mathrm{AL}$ amyloidosis is kidney transplantation, which might be accompanied by high-dose melphalan and autologous stem cell transplantation.

A very important role is played by supportive treatment in patients with AL amyloidosis due to the fact that specific treatment needs a certain time to take effect. Salt restriction is important in patients with congestive heart failure and nephrotic syndrome. Diuretic therapy and water restriction are sometimes controversial due to the intravascular water depletion and hypotension in this group of patients. Hypotension (multifactorial - heart failure, hypoproteinemia, autonomic nervous dysfunction, adrenal dysfunction) could be influenced by the use of midodrine or a small dose of mineralocorticoids. Patients with recurrent syncopes may benefit from pacemaker implantation, and ventricular arrhythmias can be improved by administration of amiodarone. Anecdotal reports refer about treatment of diarrhea by octreotide [3].

\section{Immunotherapy in AL Amyloidosis}

For the future we can expect the rapid development of immunotherapy, both active and passive immunization. In active vaccination fragments of LCs or immunoconjugates of the amino-terminal part of fibril precursors may be used as antigen [19]. Passive immunization with amyloid-reactive antibodies might enhance clearance of amyloid deposits and rapid resolution of experimentally created AL amyloidosis in mice was shown [20].

\section{Conclusion}

$\mathrm{AL}$ amyloidosis, the most common type from the group of acquired amyloidoses, represents severe diseases with limited response to treatment and unsatisfactory outcome. Only early identification of the disease and aggressive treatment could lead to the remission. The new treatment modalities, including immunotherapy, represent a promising way with hope of better survival for patients. 


\section{References}

-1 Kyle RA, Linos A, Mary Beard C, Linke RP, Gertz MA, O’Fallon M: Incidence and natural history of primary systemic amyloidosis (AL) in Olmsted Country, Minnesota: 1950 1989. Blood 1992;79:1817-1822.

-2 Obici L, Perfetti V, Palladini G, Moratti R, Amerlini G: Clinical aspects of systemic amyloid diseases. Biochim Biophys Acta 2005; 1753:11-22.

3 Palladini G, Perfetti V, Merlini G: Therapy and management of systemic AL (primary) amyloidosis. Swiss Med Wkly 2006;136:715720.

4 Tan SY, Pepys MB, Hawkins PN: Treatment of amyloidosis. Am J Kidney Dis 1995;26: 267-285.

5 Glenner GG: Amyloid deposits and amyloidosis. The $\beta$-fibrilloses. N Engl J Med 1980; 302:1283-1292.

6 Hawkins PN: Serum amyloid P component scintigraphy for diagnosis and monitoring amyloidosis. Curr Opin Nephrol Hypertens 2002;11:649-655.

7 Gertz MA, Comenzo R, Falk RH, Fermand JP, Hazenberg BP, Hawkins PN, Merlini G, Moreau P, Ronco P, Sanchorawala V, Sezer O, Solomon A, Grateau G: Definition of organ involvement and treatment response in immunoglobulin light chain amyloidosis: A consensus opinion from the 10th International Symposium on Amyloid and Amyloidosis. Am J Hematol 2005;79:319-328.
8 Gertz MA, Leung N, Lacy MQ, Dispenzieri A: Myeloablative chemotherapy and stem cell transplantation in myeloma and primary amyloidosis with renal involvement. Kidney Int 2005;68:1464-1471.

$\checkmark 9$ Palladini G, Pefetti V, Obici L, Caccialanza R, Semino A, Adami F, Cavallero G, Rustichelli R, Virga G, Merlini G: Association of melphalan and high-dose dexamethasone is effective and well tolerated in patients with AL (primary) amyloidosis who are ineligible for stem cell transplantation. Blood 2004; 103:2936-2938.

10 Merlini G: Treatment of primary amyloidosis. Semin Hematol 1995;32:60-79.

11 Comenzo RL, Vosburgh E, Falk RH: Doseintensive melphalan with blood stem-cell support for the treatment of AL amyloidosis: survival and responses in 25 patients. Blood 1998;91:3662-3670.

12 Mollee PN, Wechalekar AD, Pereira DL, Franke N, Reece D, Chen C, Stewart AK: Autologous stem cell transplantation in primary systemic amyloidosis: the impact of selection criteria on outcome. Bone Marrow Transplant 2004;33:271-277.

13 Gertz MA, Lacy MQ, Dispenzieri A, Hayman SR: Amyloidosis: diagnosis and management. Clin Lymphoma Myeloma 2005;6: 208-219.

14 Dispenzieri A, Kyle RA, Lacy MQ, Therneau TM, Larson DR, Plevak MF, Rajkumar SV, Fonseca R, Greipp PR, Witzig TE, Lust JA, Zeldenrust SR, Snow DS, Hayman SR, Litzow MR, Gastineau DA, Tefferi A, Inwards DJ, Micallef IN, Ansell SM, Porrata LF, Elliott ME, Gertz MA: Superior survival in primary systemic amyloidosis patients undergoing peripheral blood stem cell transplantation: a case-control study. Blood 2004;103:3960-3963.
15 Comenzo RL: Managing systemic lightchain amyloidosis. J Natl Compr Canc Netw 2007;5:179-187.

16 Gianni L, Bellotti V, Gianni AM, Merlini G: New drug therapy of amyloidoses: resorption of AL-type deposits with 4'-iodo-4'-deoxydoxorubicin. Blood 1995;86:855-861.

17 Dubrey SW, Burke MM, Khaghani A, Hawkins PN, Yacoub MH, Banner NR: Longterm results of heart transplantation in patients with amyloid heart disease. Heart 2001;85:202-207.

18 Maurer MS, Raina A, Hesdorffer C, Bijou R, Colombo P, Deg M, Drusin R, Haythe J, Horn E, Lee SH, Marboe C, Naka Y, Scgulman L, Scully B, Shapiro P, Prager K, Radhakrishnan J, Restaino S, Mancini D: Cardiac transplantation using extended-donor criteria organs for systemic amyloidosis complicated by hearth failure. Transplantation 2007;83:539-545.

19 Lacy MQ, Wettstein P, Dispenzieri A: Dendritic cell-based idiotype vaccination for primary systemic amyloidosis. Blood 2000; 96:164a.

20 Gillmore JD, Hawkins PN: Drug insight: emerging therapies for amyloidosis. Nat Clin Pract Nephrol 2006;2:263-270. 